\title{
Untreated hepatocellular carcinoma in Egypt: outcome and prognostic factors
}

\author{
This article was published in the following Dove Press journal: \\ Journal of Hepatocellular Carcinoma \\ 30 January 2015 \\ Number of times this article has been viewed
}

\author{
Ahmed Abdelmabood \\ Zeeneldin' \\ Salem Eid Salem' \\ Amira Diaa Darwish' \\ Mosaad Mahmoud \\ El-Gammal' \\ Marwa Mahmoud Hussein' \\ Mohamed Saadeldin ${ }^{2}$ \\ 'Medical Oncology/Hematology, \\ National Cancer Institute, Cairo \\ University, Cairo, Egypt; ${ }^{2}$ Medical \\ Oncology, Tanta Cancer Center, \\ Tanta, Egypt
}

Background: Hepatocellular carcinoma (HCC) is a common cancer worldwide as well as in Egypt with hepatitis $\mathrm{C}$ and $\mathrm{B}$, alcohol and aflatoxins being the commonest risk factors.

Aim: The objective of this study was to assess the prognostic factors affecting overall survival (OS) of untreated HCC in Egypt.

Methods: This retrospective study was conducted at Tanta Cancer Center, Egypt where 288 HCC cases who received no specific therapy and were followed-up until death were identified. The impact of possible prognostic factors on OS was assessed using the log-rank test (univariate analyses) and Cox regression method (multivariate analysis).

Results: The median OS of untreated HCC was 2.3 months (95\% confidence interval: 1.9-2.6). The 1, 3, 6, 12, 24 months OS rates were $84 \%, 42 \%, 21 \%, 9 \%$, and 3\%, respectively. All cases had died by 46 months. Male sex, advanced Child-Pugh class, the clinical presentation of ascites, cough, fatigue, and the presence of metastases were associated with poor survival $(P<0.05$ for all). In multivariate analysis; cough, presence of ascites, and Child-Pugh class were independent predictors of poor survival.

Conclusion: OS in untreated HCC in Egypt is very short. Many factors interact to produce this dismal survival.

Keywords: hepatocellular carcinoma, Egypt, prognosis, survival

\section{Introduction}

Hepatocellular carcinoma (HCC) is the most common form of primary liver cancer. ${ }^{1}$ Worldwide, liver cancer is the fifth and seventh most common cancer in men and women, respectively. Most of the burden lies in developing countries. The regions of high incidence include Eastern and South-Eastern Asia, Middle and Western Africa. It is the third most common cause of death from cancer. Its high fatality is reflected on high (0.93) mortality to incidence ratio. ${ }^{2}$ In Egypt, liver cancer is the fourth most common cancer and is the second cause of cancer mortality in both sexes. ${ }^{2}$ Risk factors for HCC are many and include viral hepatitis B (HBV) and C (HCV), cirrhosis, aflatoxins, alcohol, smoking, and male sex. ${ }^{3}$ These risk factors vary among countries, but chronic infection with $\mathrm{HBV}$ and $\mathrm{HCV}$ are the most important precursors for HCC development on a global scale, together accounting for over $80 \%$ of liver cancer cases worldwide. ${ }^{4}$ Worldwide, HCV infection is one of the most serious health problems. HCV-related liver disease can progress over several decades in an insidious manner with liver cirrhosis and HCC the advanced forms of the disease. About one quarter of subjects with HCV chronic infection are estimated to develop liver cirrhosis 15-25 years later. ${ }^{5}$ In those patients with compensated liver cirrhosis related to $\mathrm{HCV}, 1.8 \%-8.3 \%$ develop HCC each year. ${ }^{6}$ In Egypt, $\mathrm{HCV}$ is the main risk factor for $\mathrm{HCC}$ where $71 \%$ of
Correspondence: Salem Eid Salem Medical Oncology/Hematology, National Cancer Institute, Cairo University, Kasr Al-Aini St, Fom El Khalig,

Cairo I1796, Egypt

$\mathrm{Tel}+202236284 \mathrm{II}$

Fax +20225328286

Email salem.eid@nci.cu.edu.eg; salemarwa2003@yahoo.com (c) (i) (8) ( 2015 leeneldin et al. This work is published by Dove Medical Press Limited, and licensed under Creative Commons Attribution - Non Commercial (unported, v3.0) BY NC License. The full terms of the License are available at http://creativecommons.org/licenses//by-nc/3.0/. Non-commercial uses of the work are permitted without any further permission how to request permission may be found at: http://www.dovepress.com/permissions.php 
HCC cases are positive for anti-HCV antibodies. ${ }^{7}$ As different treatment modalities of HCC may prolong survival in some cases, this will not accurately reflect the prognostic values of some factors. The aim of this study was to assess the impact of various demographic and clinico-pathological factors on the survival of untreated HCC patients.

\section{Methods}

This retrospective study was conducted at Tanta Cancer Center (TCC), Ministry of Health, Gharbiah Governorate, Egypt. TCC is the largest cancer center in its governorate and serves 4.2 million people constituting $5.7 \%$ of the Egyptian population. Through TCC database, 1,009 cases with untreated HCC were identified between the years 1999 and 2007. Only patients who were followed-up until death $(n=288)$ were included in this study. The following data were collected from the medical records: age, sex, residence, occupation, history of hepatitis, smoking, date of diagnosis, presence of cirrhosis (made up based on combination of history and physical examination, laboratory abnormalities mainly liver function, radiographic based on ultrasound and computed tomography [CT] scan and in some patients through guided liver biopsy), ${ }^{8}$ clinical presentations, laboratory parameters, Child-Pugh class, site, size, number and stage of the primary tumor $(\mathrm{T})$, regional lymph node $(\mathrm{N})$ involvement, presence and site of metastases (M), histological grade, date and state of last contact. Staging was assessed based on AJCC-TNM staging system 2002. The main causes for non-treatment were the presence of comorbidities, poor liver function (Child-Pugh $>$ B), refusal of treatment, diffuse or massive tumor or extrahepatic spread (before the approval of sorafenib) precluding curative surgery, and limited access to systemic treatment or transplant due to high cost and absence of national insurance system to cover all patients in Egypt. Diagnosis was achieved by ultrasonographic guided biopsy from the lesions, HCC radiological criteria in triphasic CT (lesion $\geq 2 \mathrm{~cm}$ showed arterial enhancement followed by washout in venous and portal phases) or presence of lesion by sonar and rising AFP. The primary end point was overall survival (OS). Secondary end points were the impact of different demographic and clinicopathological characteristics on OS. OS was defined as the time from diagnosis until death. The study was approved by the NCI Institutional Review Board.

\section{Statistical analyses}

SPSS $^{\circledR}$ (Statistical Package for the Social Sciences) version 21 (IBM Corporation, Armonk, NY, USA) and Graph Prism ${ }^{\circledR}$ for windows version 5.01 (GraphPad Software, Inc., La Jolla, CA, USA) were used in the analyses. Kaplan-Meier method was used in survival calculations and differences between groups were calculated using the log-rank test. Cox regression analysis was used to test the impact on OS of factors with $P$-value $\leq 0.05$ in the log-rank test. A probability $(P)$ equal to or less than 0.05 (two-sided) was considered statistically significant.

\section{Results}

This retrospective study included 288 cases of untreated HCC who attended TCC between 1999 and 2007. Age ranged between 28 and 85 years with a median of 59.5 years and the mean \pm standard deviation was $59.9 \pm 11.0$ (Table 1). Male to female ratio was 5.7:1. About two thirds of the patients were rural inhabitants and farmers constituted $41 \%$ of patients. Almost two-thirds of the patients $(64.2 \%)$ had a smoking history. Viral hepatitis markers status was documented in only 48 patients and was positive in $79 \%$ with hepatitis $\mathrm{C}$ being the most predominant type (92\%). About four fifths of patients ( $82 \%$ ) had some evidence of cirrhosis; clinical, imaging or laboratory. The most common clinical presentations were abdominal pain, fatigue, and ascites. Cough and encephalopathy were infrequently encountered. Most patients had Child-Pugh class B ( $\sim 82 \%)$.

Tumors involved the right liver lobe more than the left (47.9\% versus $17.1 \%$ ) and both lobes were involved in $35 \%$ (Table 2). The lesions were multiple in $53.8 \%$ of cases. The diagnosis was confirmed histologically in $63 \%$ of patients, while $11 \%$ had a classic triphasic CT picture of HCC (arterial enhancement and rapid venous washout), and the rest of the cases $(26 \%)$ were diagnosed based on elevated AFP together with the presence of cirrhosis and hepatic focal lesions in imaging studies. Most cases that were diagnosed histologically $(80.7 \%)$ were of low grade. The median tumor diameter was $6.0 \mathrm{~cm}$ (range $1.5-15.0 \mathrm{~cm}$ ) and about two thirds of the patients had tumor size more than $5.0 \mathrm{~cm}$. Most patients had T3-4, N0 and M0 tumors. Stages III and IV were the commonest stages and bone was the commonest site of metastasis.

\section{OS}

The median OS of untreated HCC was 2.3 months $(95 \%$ confidence interval [CI]: 1.9-2.6). The 1, 3, 6, 12, 24 months OS rates were $84 \%, 42 \%, 21 \%, 9 \%$, and $3 \%$, respectively. All the 288 cases had died by 46 months (Figure 1).

The impact of various clinical and pathological features on OS was explored (Table 3). Using the log-rank test, it was shown 
Table I Clinical characteristics of 288 untreated HCC patients followed to death

\begin{tabular}{|c|c|}
\hline Characteristic & Number (\%) \\
\hline \multicolumn{2}{|l|}{ Demographics } \\
\hline Age (years) (mean $\pm S D)$ & $59.9 \pm 11.0$ \\
\hline \multicolumn{2}{|l|}{ Sex } \\
\hline Male & $245(85.1)$ \\
\hline Female & $43(14.9)$ \\
\hline \multicolumn{2}{|l|}{ Residence } \\
\hline Rural & $202(70.1)$ \\
\hline Urban & $86(29.9)$ \\
\hline \multicolumn{2}{|l|}{ Occupation } \\
\hline Farmer & I I 8 (4I.0) \\
\hline Unemployed & $91(31.6)$ \\
\hline Employee & $38(13.2)$ \\
\hline Housewife & $4 I(14.2)$ \\
\hline \multicolumn{2}{|l|}{ Risk factors } \\
\hline Smoking & 229 \\
\hline No & $82(35.8)$ \\
\hline Yes & 147 (64.2) \\
\hline Hepatitis & 48 \\
\hline Positive & $38(79.2)$ \\
\hline Negative & $10(20.8)$ \\
\hline Known hepatitis & 38 \\
\hline C & 27 (7I.I) \\
\hline B & $3(7.9)$ \\
\hline $\mathrm{C}$ and $\mathrm{B}$ & $8(21.1)$ \\
\hline \multicolumn{2}{|l|}{ Cirrhosis } \\
\hline Yes & $237(82.3)$ \\
\hline No & $5 \mathrm{I}(\mathrm{I7.7)}$ \\
\hline \multicolumn{2}{|l|}{ Clinical presentations } \\
\hline \multicolumn{2}{|l|}{ Fatigue } \\
\hline No & $13(4.5)$ \\
\hline Yes & $275(95.5)$ \\
\hline \multicolumn{2}{|l|}{ Cough } \\
\hline No & $212(73.6)$ \\
\hline Yes & $76(26.4)$ \\
\hline \multicolumn{2}{|l|}{ Ascites } \\
\hline No & $37(12.8)$ \\
\hline Yes & $25 I(87.2)$ \\
\hline \multicolumn{2}{|l|}{ Encephalopathy } \\
\hline No & $25 \mathrm{I}(87.2)$ \\
\hline Yes & $37(12.8)$ \\
\hline \multicolumn{2}{|l|}{ Child-Pugh class } \\
\hline A & $22(7.6)$ \\
\hline$B$ & $236(81.9)$ \\
\hline $\mathrm{C}$ & $30(10.4)$ \\
\hline
\end{tabular}

Abbreviations: HCC, hepatocellular carcinoma; TCC, Tanta Cancer Center; SD, standard deviation.

that age, residence, smoking, and number of lesions had no impact on OS while female sex, Child-Pugh A, non-metastatic disease and absence of ascites, cough or fatigue were significantly associated with better OS $(P<0.05$ for all). Although cases with a low AFP level showed better survival compared to those with elevated baseline level, this difference was not statistically significant. Multivariate analysis showed that higher ChildPugh class, cough, and ascites were independent predictors of
Table 2 Tumor and pathological characteristics of 288 untreated $\mathrm{HCC}$ at TCC

\begin{tabular}{ll}
\hline Characteristic & Number (\%) \\
\hline Liver lobe site & 263 \\
Right & $126(47.9)$ \\
Left & $45(17.1)$ \\
Multiple & $92(35.0)$ \\
No of lesions & \\
Single & $133(46.2)$ \\
Multiple & $155(53.8)$ \\
Histologic grade & 114 \\
Low (I-2) & $92(80.7)$ \\
High (3-4) & $22(19.3)$ \\
Tumor size & 238 \\
Median (range) & $6.0(1.5-15.0)$ \\
$\leq 5$ cm & $8 I(34.0)$ \\
$>5$ cm & $157(66.0)$ \\
T stage & 256 \\
I & $2(0.8)$ \\
2 & $4(I .6)$ \\
3 & $147(57.4)$ \\
4 & $103(40.2)$ \\
N stage & 280 \\
0 & $26 I(93.2)$ \\
I & $19(6.8)$ \\
M stage & 285 \\
0 & $18 I(63.5)$ \\
I & $104(36.5)$ \\
TNM staging & 268 \\
I & $2(0.7)$ \\
II & $2(0.7)$ \\
III & $160(59.7)$ \\
IV & $104(38.8)$ \\
Bone of metastases & 104 \\
Lung & $48(46.2)$ \\
Non-regional LN & $27(26)$ \\
Suprarenal & $26(25)$ \\
\hline
\end{tabular}

Abbreviations: HCC, hepatocellular carcinoma; TCC, Tanta Cancer Center; $\mathrm{T}$, tumor; $\mathrm{N}$, regional lymph node; $\mathrm{M}$, metastases.

poor OS. The hazard of death in patients with Child-Pugh class $\mathrm{B}$ or $\mathrm{C}$ was almost two times that with class A (95\% CI: 1.1-3.8). The hazard of death in patients with ascites was almost three times that without such finding (95\% CI: 1.6-5.3). The hazard of death in patients presenting with cough was 2.3 times that without cough (95\% CI: 1.7-3.1) (Table 4).

\section{Discussion}

HCC is a major health problem in Egypt and many patients present with advanced disease beyond curative surgery and effective local and regional therapies. With the exception of a certain group of patients with resectable disease and adequate liver reserve or those who underwent transplant, treatment of HCC remains palliative with minimal survival benefit. ${ }^{2,9}$ 


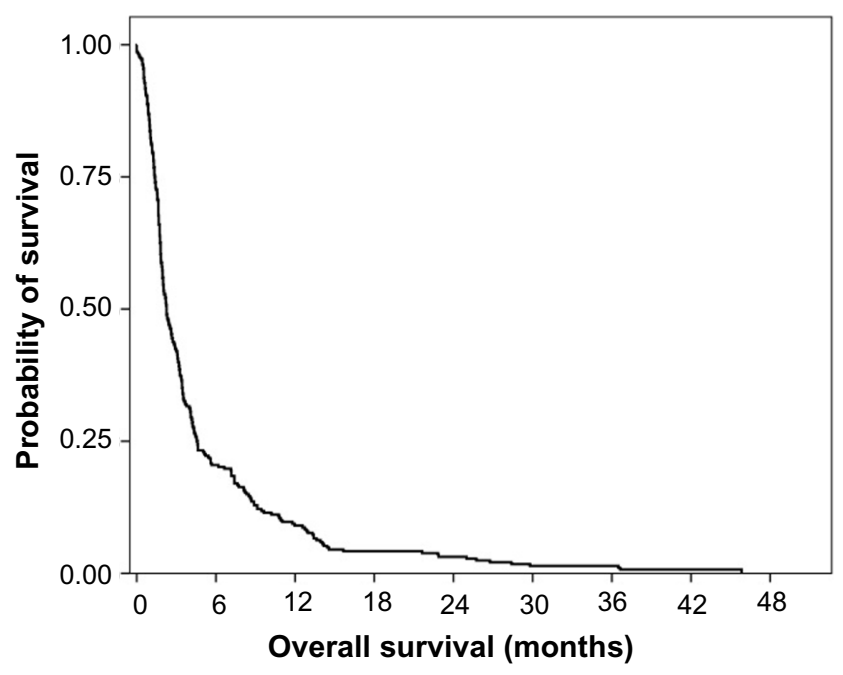

Figure I Overall survival in 288 untreated hepatocellular carcinoma patients.

In the current study, we assessed the prognostic factors of unselected HCC patients who did not receive any treatment for their disease. Several Western and Eastern trials reported on similar cohorts of patients to assess the natural course of the disease. Cabibbo et $\mathrm{l}^{10}$ assessed the prognostic factors in 320 Italian patients who were not candidates for active treatment, and Llovet et $\mathrm{al}^{11}$ reported on 102 Spanish patients, Yeung et a ${ }^{12}$ studied 106 Chinese patients who were not candidates for curative surgical treatment while Pawarode et $\mathrm{al}^{13}$ reported on 157 patients from Thailand who received no active treatment for their HCCs.

The advantage of the current study is that it included all untreated patients and not only those unfit for therapy as some patients were potentially eligible for some form of therapy but did not receive it because of refusal or unavailability of treatment. So the current study may give more insight about the natural course or biology of HCC which was not interrupted by treatment while the majority of patients in previous trials had certain adverse prognostic factors preventing them from treatment. So, most of these trials reflect the behavior of patients who were unfit for active treatment. Moreover, patients included in the current study may be representative of the whole Egyptian population as the study was done at TCC. TCC represents Gharbiah cancer registry which is the first national cancer registry in Egypt. ${ }^{14}$

Some of the limitations of the present study, like that of Cabibbo et $\mathrm{al}^{10}$ and Pawarode et $\mathrm{al},{ }^{13}$ are that the study was retrospective and that it did not allow for molecular tests to assess the molecular biology of the disease and having some missing data related to some key factors eg, hepatitis. Our patients are younger compared to the study
Table 3 Univariate analyses of factors affecting overall survival in untreated $\mathrm{HCC}$

\begin{tabular}{|c|c|c|c|c|}
\hline Variable & No & $\begin{array}{l}6 \text { months } \\
\text { OSR (SE) }\end{array}$ & $\begin{array}{l}\text { I } 2 \text { months } \\
\text { OSR (SE) }\end{array}$ & $P$-value \\
\hline \multicolumn{5}{|l|}{ Age } \\
\hline$<59$ years & 138 & $21.7(3.5)$ & $8.0(2.3)$ & \\
\hline$\geq 59$ years & 150 & $19.3(3.2)$ & $10.0(2.4)$ & 0.872 \\
\hline \multicolumn{5}{|l|}{ Sex } \\
\hline Male & 245 & $18.4(2.5)$ & $7.3(1.7)$ & \\
\hline Female & 43 & $32.6(7.1)$ & $18.6(5.9)$ & 0.024 \\
\hline \multicolumn{5}{|l|}{ Residence } \\
\hline Village & 202 & $20.8(2.9)$ & $8.4(2.0)$ & \\
\hline Town & 86 & $19.8(4.3)$ & $10.5(3.3)$ & 0.962 \\
\hline \multicolumn{5}{|l|}{ Smoking } \\
\hline No & 82 & $22.0(4.6)$ & $12.2(3.6)$ & \\
\hline Yes & 147 & $17.7(3.1)$ & $6.1(2.0)$ & 0.097 \\
\hline \multicolumn{5}{|l|}{ Cough } \\
\hline No & 212 & $26.4(3.0)$ & II.8 (2.2) & \\
\hline Yes & 76 & $3.9(2.2)$ & $1.3(1.3)$ & $<0.001$ \\
\hline \multicolumn{5}{|l|}{ Ascites } \\
\hline No & 37 & $70.3(7.5)$ & $45.9(8.2)$ & \\
\hline Yes & 251 & I3.I (2.I) & $3.6(1.2)$ & $<0.001$ \\
\hline \multicolumn{5}{|l|}{ Fatigue } \\
\hline No & 13 & $53.8(13.8)$ & $30.8(12.8)$ & \\
\hline Yes & 275 & $18.9(2.4)$ & $7.6(1.6)$ & 0.005 \\
\hline \multicolumn{5}{|l|}{ Child-Pugh } \\
\hline A & 22 & $50.0(10.7)$ & $36.4(10.3)$ & \\
\hline$B$ & 236 & $20.3(2.6)$ & $7.6(1.7)$ & \\
\hline C & 30 & $0(0)$ & $0(0)$ & $<\mathbf{0 . 0 0 1}$ \\
\hline \multicolumn{5}{|l|}{ Child-Pugh } \\
\hline A & 22 & $50.0(10.7)$ & $36.4(10.3)$ & \\
\hline$B+C$ & 266 & $18.0(2.4)$ & $6.8(1.5)$ & $<0.001$ \\
\hline \multicolumn{5}{|l|}{ AFP } \\
\hline$<400$ & 61 & I4.8 (4.5) & $6.6(3.2)$ & \\
\hline$>400$ & 77 & $10.4(3.5)$ & $5.2(2.5)$ & 0.057 \\
\hline \multicolumn{5}{|c|}{ Lesion numbers } \\
\hline Single & 133 & $16.5(3.2)$ & $8.3(2.4)$ & \\
\hline Multiple & 155 & $23.9(3.4)$ & $9.7(2.4)$ & 0.286 \\
\hline \multicolumn{5}{|l|}{ Metastases } \\
\hline No & 184 & $23.4(3.1)$ & II.4 (2.3) & \\
\hline Yes & 104 & I5.4 (3.2) & $4.8(2.1)$ & 0.018 \\
\hline
\end{tabular}

Note: Bold values indicate significant values.

Abbreviations: AFP, alpha-fetoprotein; HCC, hepatocellular carcinoma; OSR, overall survival rate; $95 \% \mathrm{CI}, 95 \%$ confidence interval; SE, standard error.

Table 4 Multivariate analysis of factors affecting overall survival in untreated HCC

\begin{tabular}{lllll}
\hline & HR & CILB & CIUB & P-value \\
\hline Sex (male vs female) & $\mathrm{I} .234$ & 0.845 & $\mathrm{I} .800$ & 0.276 \\
Child-Pugh class (B + C vs A) & 1.999 & 1.064 & 3.753 & $\mathbf{0 . 0 3 I}$ \\
Tumor size $(<5 \mathrm{~cm}$ vs $>5 \mathrm{~cm})$ & 0.803 & 0.602 & $\mathrm{I} .072$ & 0.136 \\
Metastasis (Yes vs no) & 1.230 & 0.927 & $\mathrm{I} .633$ & $0.15 \mathrm{I}$ \\
Cough (Yes vs no) & 2.294 & $\mathrm{I} .678$ & 3.137 & $<\mathbf{0 . 0 0 I}$ \\
Fatigue (Yes vs no) & $\mathrm{I} .124$ & 0.446 & 2.829 & 0.805 \\
Ascites (Yes vs no) & 2.912 & 1.596 & 5.312 & $<\mathbf{0 . 0 0 I}$ \\
\hline
\end{tabular}

Note: Bold values indicate significant values.

Abbreviations: HCC, hepatocellular carcinoma; HR, hazard ratio; CIUB, upper boundary of the $95 \%$ confidence interval; CILB, lower boundary of the $95 \%$ confidence interval; vs, versus. 
by Cabibbo et al, (59.5 versus 68 years) with two thirds of them being rural inhabitants with male predominance which is in agreement with other Egyptian studies ${ }^{14-18}$ as well as some other countries. ${ }^{19}$ This may be explained by the higher exposure to HCV and HBV largely due to a massive public health campaign by parenteral antischistosomal therapy extended from the 1950s through the 1980s and the indoor nature of females in rural areas with less exposure to risk factors. ${ }^{20}$ Also, rural areas store food grains more than urban areas with possible contamination by aflatoxins. Moreover, pesticides may play a role in hepatocarcinogenesis and consequently HCCs. ${ }^{21}$ Our patients are older than the Thailand group (50.9 years) with a slightly similar male to female ratio (4.6:1) which may be due to some similarities in population activities and distribution. ${ }^{13}$ At least one presenting symptom is present in our cases but with a higher percentage than the Thailand group. The presence of symptomatic disease reflects the worse state at presentation of our cases which worsen survival like the Thailand patients. ${ }^{13}$ Hepatitis viral status was documented in only about $11 \%$ of cases, with hepatitis $\mathrm{C}$ being the most dominant type in agreement with other Egyptian and European studies and in contrast to eastern studies in which HBV was the predominant type. ${ }^{13,22-24}$ Documentation of diagnosis was dominantly achieved by biopsy ( $63 \%$ vs $19 \%$ ) while it was mainly by radiological and laboratory tests in the Italian study which was due to the old trends of diagnosis of HCC in Egypt based on histopathological diagnosis which showed a dramatic shift to radiological and laboratory diagnosis nowadays. Also, AFP values were higher (1,474 versus $35 \mathrm{ng} / \mathrm{L})$ reflecting the advanced stage and severity of cirrhosis in our cases but tumor distribution was similar in both studies - both lobes being involved in one third, and multiple in about two thirds of cases preventing local treatment and resulting in bad outcome as most of these cases had no chance for curative treatment. In spite of different staging systems used, most of our cases are at an advanced stage and had larger tumor size similar to the Italian group. ${ }^{10}$

Untreated HCC patients usually have very short survival. ${ }^{25}$ In the current study, OS was 2.3 months. This poor outcome could be related to late presentation as most patients present with stage III or IV, advanced cirrhosis, and poor liver functional reserve. Late presentation could be related to decreased awareness among patients and possibly primary health care physicians. This could be due to the fact that symptoms and signs of HCC could be attributed to the longlasting underlying cirrhosis. Late presentation could also be related to absence of nationwide HCC screening programs.
Such programs ${ }^{26}$ detect HCC at earlier and more treatable stages. It could also be related to a shortage of "state of art" therapies for HCC that covers the majority of Egypt eg, expertise in liver resection and transplantation, limited liver donors, expertise and equipment for local and ablative therapies, expertise and facilities for TACE or radio-embolization, and the wide availability of the targeted therapy sorafenib. Most of the patients in the current study were farmers and rural inhabitants and hence may lack comprehensive health insurance that ensures reasonable access to specific HCC therapies.

The 2.3 month median OS in the current study was comparable to the median OS of 2-3 months reported by Yeung et al, Pawarode et al, and Kim et al. ${ }^{12,13,27}$ However, the Italian group reported a higher median OS (6.8 months) and 12 month OS rate (32\%) and Llovet et al reported a higher 12 month and 24 month OS rate (54\% and 40\% respectively). ${ }^{10,11}$ This could be related to the better prognosis of their patients as two thirds of Llovet et al's patients had Child-Pugh class A. Thus, the prognosis of untreated HCC in Egyptian patients is worse than the European patients for the reason mentioned earlier.

Using univariate analysis, factors associated with low burden disease (non-metastatic disease), fewer symptoms (absence of ascites, fatigue or cough) or those with good liver reserve (Child-Pugh A), and female sex are significantly associated with improved survival. Similar to our results, absence of ascites was associated with improved survival in the Italian group in univariate analysis. But in contrast, factors affecting survival in their study were INR, bilirubin, performance status (not assessed in our study), and low albumin reflecting different disease biology. ${ }^{10}$ In previous studies with similar design, multivariate analyses showed many independent prognostic factors, with AFP, bilirubin, performance status and stage being the most consistent between these trials. In agreement with Llovet et al, ${ }^{11}$ the current study showed that extrahepatic spread was a predictor of poor survival. Extrahepatic spread is usually associated with high burden of the disease and it precludes local treatments. Extrahepatic spread combined with the absence of effective systemic treatments is responsible for the dismal outcome in that advanced stage of the disease. Again, a higher Child-Pugh class and fatigue were independent factors of poor survival mostly because they reflect the underlying poor liver reserve. Fatigue may also reflect a bad PS status, consistent with Cabibbo et al who concluded that PS was an independent prognostic factor. ${ }^{10}$ Although there were common prognostic factors shared between trials, there 
were still several other factors associated with outcome in HCC. This may reflect the aggressive biology of the disease independent on certain single factor. So if we consider the aggressive biology of the disease, and the limited treatment options for HCC patients as well as the limited resources or access to treatment for most of Egyptian patients like sorafenib or liver transplant, we found that HCC is a fatal disease and constitutes a major national problem. So we have to find other effective treatment modalities (with less success expected) or try to stress the importance of screening programs which can enable diagnosis at an early stage with the opportunity for treatment with curative intent. But the most valuable solution is to put more effort into a prevention program, whether through prevention of infection by viral hepatitis or treating it at early stages before causing cirrhosis which is the main risk factor for HCC in Egypt.

\section{Conclusion}

$\mathrm{HCC}$ in Egypt is an aggressive disease and OS in untreated HCC is very short. Many factors interact to produce this dismal survival. As most treatment modalities are not effective, much effort should be put into the field of prevention and screening programs to get rid of the problem.

\section{Acknowledgment}

We express our appreciation to all staff of Tanta Cancer Center, Egypt particularly Dr Mohamed Ramadan and Dr Mohamed El-Sabrout for their help during the conduct of this study.

\section{Disclosure}

This work is investigator-initiated with no external funding or support. The authors have no conflicts of interest to disclose.

\section{References}

1. Poustchi H, Sepanlou S, Esmaili S, Mehrabi N, Ansarymoghadam A. Hepatocellular carcinoma in the world and the Middle East. Middle East J Dig Dis. 2010;2(1):31-41.

2. globocan.iarc.fr [homepage on the Internet]. Ferlay J, Shin HR, Bray F, Forman D, Mathers C, Parkin DM. GLOBOCAN 2008 v1.2, Cancer Incidence and Mortality Worldwide: IARC Cancer Base No 10. Lyon, France: IARC; 2010. Available from: http://globocan.iarc.fr. Accessed October 16, 2014.

3. Ahmad J, Rabinovitz M. In: Carr I, editor. Etiology and Epidemiology of Hepatocellular Carcinoma in Current Clinical Oncology: Hepatocellular Cancer: Diagnosis and Treatment. Totowa: Humana Press Inc.; 2005:1-22.

4 Bosch FX, Ribes J, Borras J. Epidemiology of primary liver cancer. Semin Liver Dis. 1999;19(3):271-285.

5. Alberti A, Chemello L, Benvegnù L. Natural history of hepatitis C. J Hepatol. 1999;31 Suppl 1:17-24.

6. Alazawi W, Cunningham M, Dearden J, Foster GR. Systematic review: outcome of compensated cirrhosis due to chronic hepatitis $\mathrm{C}$ infection. Aliment Pharmacol Ther. 2010;32(3):344-355.
7. Rahman El-Zayadi A, Abaza H, Shawky S, Mohamed MK, Selim OE, Badran HM. Prevalence and epidemiological features of hepatocellular carcinoma in Egypt-a single center experience. Hepatol Res. 2001;19(2): 170-179.

8. Heidelbaugh JJ, Bruderly M. Cirrhosis and chronic liver failure: Part I. diagnosis and evaluation. Am Fam Physician. 2006;74(5):756-762.

9. Llovet JM. Updated treatment approach to hepatocellular carcinoma. J Gastroenterol. 2005;40(3):225-235.

10. Cabibbo G, Maida M, Genco C, et al. Natural history of untreatable hepatocellular carcinoma: A retrospective cohort study. World $J$ Hepatol. 2012;4(9):256-261.

11. Llovet JM, Bustamante J, Castells A, et al. Natural history of untreated nonsurgical hepatocellular carcinoma: rationale for the design and evaluation of therapeutic trials. Hepatology. 1999;29(1):62-67.

12. Yeung YP, Lo CM, Liu CL, Wong BC, Fan ST, Wong J. Natural history of untreated nonsurgical hepatocellular carcinoma. Am J Gastroenterol. 2005;100(9):1995-2004.

13. Pawarode A, Voravud N, Sriuranpong V, Kullavanijaya P, Patt YZ. Natural history of untreated primary hepatocellular carcinoma: a retrospective study of 157 patients. Am J Clin Oncol. 1998; 21(4):386-391.

14. World Health Organization. The Gharbiah Population-Based Cancer Registry. Cancer in Egypt, Gharbiah, 2007. Regional Office for the Eastern Mediterranean. Available from: http://www.emro.who.int/ncd/ pdf/cancer_registry_Egypt.pdf. Accessed October 16, 2014.

15. el-Zayadi AR, Badran HM, Barakat EM, et al. Hepatocellular carcinoma in Egypt: a single center study over a decade. World J Gastroenterol. 2005;11(33):5193-5198.

16. el-Zayadi AR, Badran HM, Shawky S, Emara S, El-Bareedy A, Sobhi M. Effect of surveillance for hepatocellular carcinoma on tumor staging and treatment decisions in Egyptian patients. Hepatol Int. 2010;4(2): 500-506.

17. Noaman M, Labib N, Radwan G. Prognostic factors for survival of patients with hepatocellular carcinoma in National Cancer Institute, Cairo University. Journal of American Science. 2011;7(9):831-839.

18. Zeeneldin AA, Salem SE, Tabashy RH, Ibrahim AA, Alieldin NH. Transarterial chemoembolization for the treatment of hepatocellular carcinoma: A single center experience including 221 patients. J Egypt Natl Canc Inst. 2013;25(3):143-150.

19. Yip WM, Hung HG, Lok KH, Li KF, Li KK, Szeto ML. Outcome of inoperable hepatocellular carcinoma patients receiving transarterial chemoembolisation: a real-life retrospective analysis in a Hong Kong regional hospital. Hong Kong Med J. 2009;15(5):339-345.

20. Habib M, Mohamed MK, Abdel-Aziz F, et al. Hepatitis C virus infection in a community in the Nile Delta: risk factors for seropositivity. Hepatology. 2001;33(1):248-253.

21. Abdel-Wahab M, Mostafa M, Sabry M, el-Farrash M, Yousef T. Aflatoxins as a risk factor for hepatocellular carcinoma in Egypt, Mansoura Gastroenterology Center study. Hepatogastroenterology. 2008;55(86-87):1754-1759.

22. Ahmed L, El-Rooby AS, Rarrag A, Salama Z. Prevalence of hepatitis B virus in patients suffering from primary hepatocellular carcinoma. J Egypt Med Assoc. 1986;69:363-371.

23. Sacco R, Bertini M, Petruzzi P, et al. Clinical impact of selective transarterial chemoembolization on hepatocellular carcinoma: A cohort study. World J Gastroenterol. 2009;15(15):1843-1848.

24. Paul SB, Gamanagatti S, Sreenivas V, et al. Trans-arterial chemoembolization (TACE) in patients with unresectable Hepatocellular carcinoma: experience from a tertiary care centre in India. Indian J Radiol Imaging. 2011;21(2):113-120.

25. Falkson G, Cnaan A, Schutt AJ, Ryan LM, Falkson HC. Prognostic factors for survival in hepatocellular carcinoma. Cancer Res. 1988; 48(24 Pt 1):7314-7318.

26. Izzo F, Piccirillo M, Albino V, et al. Prospective screening increases the detection of potentially curable hepatocellular carcinoma: results in 8,900 high-risk patients. HPB (Oxford). 2013;15(12):985-990.

27. Kim UB, Doo CJ, Baek SH, et al. Natural history and prognostic factors of primary hepatocellular carcinoma: study of 70 untreated patients. Korean J Intern Med. 1989;4(2):136-141. 
Journal of Hepatocellular Carcinoma

Dovepress

\section{Publish your work in this journal}

The Journal of Hepatocellular Carcinoma is an international, peerreviewed, open access journal that offers a platform for the dissemination and study of clinical, translational and basic research findings in this rapidly developing field. Development in areas including, but not limited to, epidemiology, vaccination, hepatitis therapy, pathology and molecular tumor classification and prognostication are all considered for publication. The manuscript management system is completely online and includes a very quick and fair peer-review system, which is all easy to use. Visit http://www.dovepress.com/testimonialsphp to read real quotes from published authors.

\footnotetext{
Submit your manuscript here: http://www.dovepress.com/journal-of-hepatocellular-carcinoma-journal
} 